\title{
KONTRIBUSI KOMPOSISI TANAMAN AGROFORESTRI TERHADAP PENDAPATAN PETANI KELURAHAN PINANG JAYA KOTA BANDAR LAMPUNG
}

\author{
(Contribution Of Agroforestry Plant Composition Of Farmers'Income Pinang Jaya Village \\ Bandar Lampung City)
}

\author{
Shelva Ayuniza, Susni Herwanti, Christine Wulandari, Hari Kaskoyo \\ Jurusan Kehutanan, Fakultas Pertanian, Universitas Lampung. \\ Jl Sumantri Bojonegoro, Gedung Meneng, Bandar Lampung, Lampung 35145 \\ Email : shelvaayuniza841@gmail.com
}

\begin{abstract}
Agroforestry is a utilization technique by combining woody plants (forestry) with crops, plantation crops, and livestock that are managed on one land. The agroforestry system can provide a better function, in terms of ecology, economy, and social culture that is important for agroforestry farming communities, one of which can provide income for farmers. This study aims to analyze how much the contribution of agroforestry plant composition to farmers' income. This research was conducted in Pinang Jaya Sub-District, Kemiling District, Bandar Lampung. To analyze the income, it is done by tabulating several groups of crop composition and calculating the income of farmers where the revenue is reduced by the cost of production. From the analysis and calculation results obtained eight plant compositions where composition $V$ gets the highest income of Rp. 25.550.000 / kk / ha / year with cocoa (Theobroma cacao) and cloves (Eugenia aromatica) combined with petai plants (Parkia speciosa), papaya (papaya) Carica papaya), banana (Musa sp), jengkol (Pithecellobium lobatum), areca nut (Pinanga kuhlii), and durian (Durio zibethinus).
\end{abstract}

Keywords : agroforestry, crop composition, income.

Abstrak

Agroforestry merupakan teknik pemanfaatan dengan menggabungkan tanaman kayu (kehutanan) dengan tanaman perkebunan, dan peternakan yang dikelola di satu lahan. Sistem agroforestri dapat memberikan fungsi yang lebih baik, dalam hal ekologi, ekonomi, dan budaya sosial yang penting bagi masyarakat petani agroforestri, salah satunya dapat memberikan pendapatan bagi petani. Penelitian ini bertujuan untuk menganalisis seberapa besar kontribusi komposisi tanaman agroforestri terhadap pendapatan petani. Penelitian ini dilakukan di Kelurahan Pinang Jaya, Kecamatan Kemiling, Bandar Lampung. Untuk menganalisis pendapatan, dilakukan dengan melakukan tabulasi beberapa kelompok komposisi tanaman dan menghitung pendapatan petani dimana pendapatan dikurangi dengan biaya produksi. Dari hasil analisis dan perhitungan diperoleh delapan komposisi tanaman dimana komposisi $V$ mendapatkan pendapatan tertinggi sebesar Rp. 25.550.000 / kk / ha / tahun dengan tanaman kakao (Theobroma cacao) dan cengkeh (Eugenia aromatica) yang dikombinasikan dengan tanaman petai (Parkia speciosa), pepaya (papaya) Carica pepaya), pisang (Musa sp), jengkol (Pithecellobium lobatum), pinang (Pinanga kuhlii), dan durian (Durio zibethinus)

Kata kunci: agroforestry, komposisi tanaman, pendapatan

PENDAHULUAN

Agroforestri merupakan teknik pemanfaatan lahan dengan cara mengkombinasikan antara tanaman kayu-kayuan (kehutanan) dengan tanaman pertanian, tanaman perkebunan, maupun peternakan yang dikelola pada satu lahan (Tiurmasari et 
al., 2016). Penggunaan sistem agroforestri tersebut dapat memberikan fungsi yang lebih baik, dari segi ekologi, ekonomi, dan sosial budaya (Mbolo et al., 2016).

Selama ini sistem agroforestri menjadi salah satu cara untuk mengatasi terjadinya pengalihgunaan lahan akibat meningkatnya jumlah penduduk yang menyebabkan kebutuhan terhadap sandang, pangan, dan papan semakin tinggi. Pengelolaan lahan dengan sistem agroforestri di Provinsi Lampung banyak diterapkan di hutan rakyat. Potensi yang dimiliki oleh hutan rakyat cukup besar sehingga mampu menyediakan bahan baku industri kehutanan (Olivi et al., 2015).

Masyarakat yang mengelola lahan dengan sistem agroforestri ini pada umumnya masyarakat yang memiliki lahan yang minim namun mempunyai tujuan agar memperoleh pendapatan dalam waktu yang singkat maupun dalam jangka panjang (tahunan). Menurut Widiarti dan Prajadinata (2008) bahwa pola agroforestri mampu memberikan penghasilan atau pendapatan yang bervariasi yaitu bersifat rutin, harian, mingguan, bulanan, musiman, hingga tahunan sehingga sistem ini dapat memberikan hasil secara berkelanjutan bagi petani yang mengelola.

Pengelolaan lahan dengan sistem agroforestri ini tidak terlepas dari pengetahuan petani terhadap karakteristik pengelolaan lahan salah satunya jenis tanaman yang dipilih untuk dibudidayakan (Anwar, 2012).
Pada umumnya jenis tanaman yang dibudidayakan dapat mempengaruhi hasil panen dan pendapatan petani. Sesuai dengan pernyataan Ayu et al. (2015) bahwa jenis tanaman merupakan salah satu faktor yang berpengaruh terhadap pendapatan, apabila jenis tanaman yang dibudidayakan semakin banyak maka akan memberikan pendapatan yang lebih tinggi. Sehingga perlu adanya komposisi tanaman agroforestri pada lahan yang berfungsi untuk menjaga keseimbangan ekosistem dan mampu meningkatkan pendapatan petani.

Komposisi tanaman yang tepat mampu memberikan fungsi ekonomi dalam jangka panjang dan jangka pendek. Menurut Qurniati et al., (2017) tanaman Multi Purpose Trees Species (MPTS) mampu memberikan pendapatan dalam jangka panjang karena tanaman jenis ini hanya dapat dipanen satu tahun sekali, sedangkan tanaman perkebunan dan pertanian merupakan jenis tanaman yang mampu memberikan pendapatan dalam jangka pendek.

Beberapa peneliti telah melakukan penelitian mengenai kontribusi komposisi tanaman agroforestri yang memperlihatkan pendapatan petani agroforestri lebih besar dibandingkan non agroforestri (Wanderi et al 2019; Olivi et al 2015; Syofiandi et al 2016). Namun, pendapatan petani agforestri di hutan rakyat Pinang Jaya ini belum diketahui karena pendapatan yang akan dianalisis berupa pendapatan tertinggi yang dilihat dari pengelompokkan komposisi tanaman Oleh sebab itu, 
penelitian ini bertujuan untuk menganalisis komposisi tanaman yang dibudidayakan untuk mengetahui pendapatan masyarakat petani agroforestri pada hutan rakyat di Kelurahan Pinang Jaya.

\section{METODE PENELITIAN}

Penelitian ini dilaksanakan di Kelurahan Pinang Jaya Kecamatan Kemiling Bandar Lampung pada bulan Januari- Februari 2020.

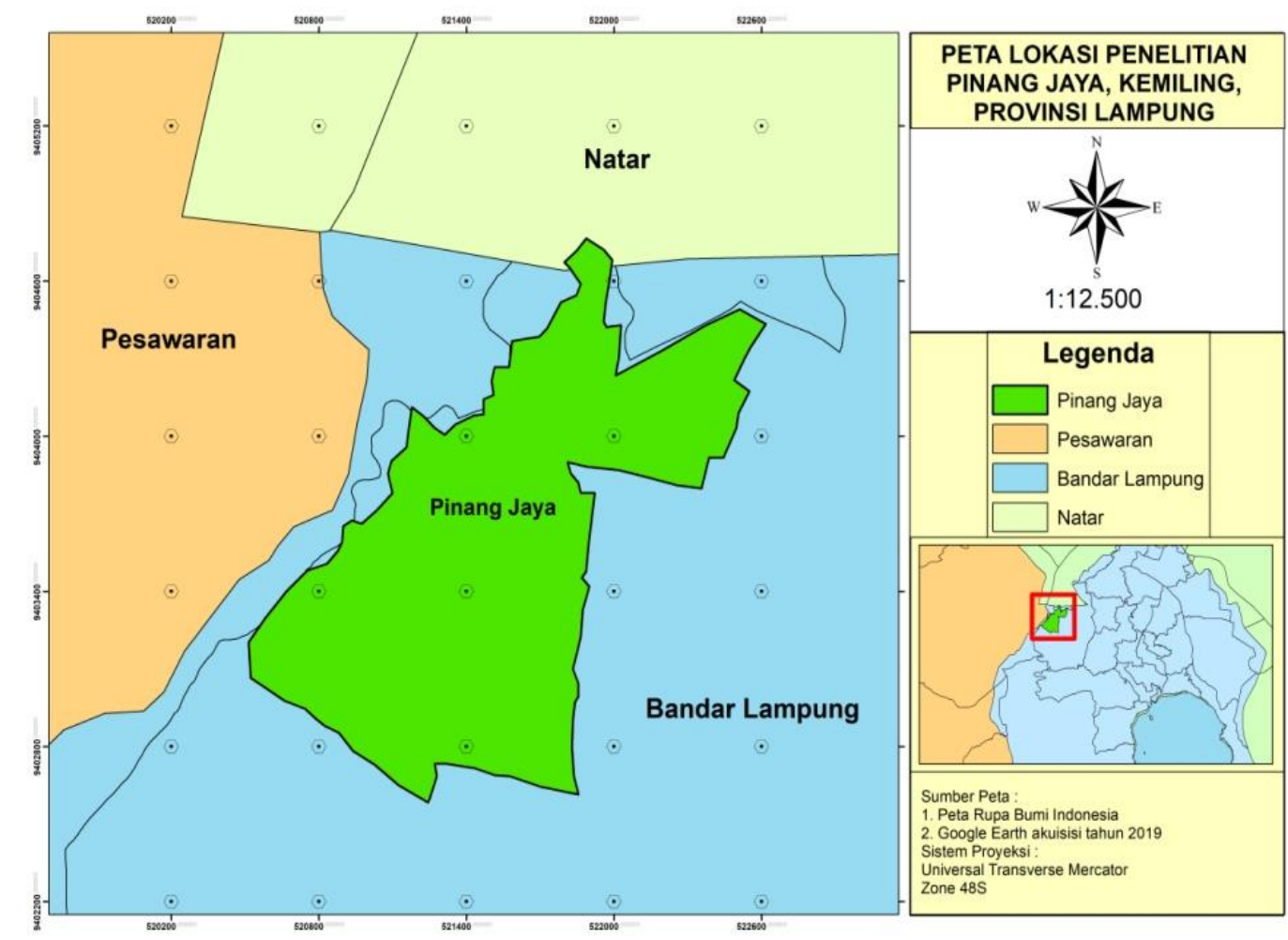

Gambar 1. Peta Lokasi Penelitian (Research location map)

Penelitian dilakukan di Kelurahan Pinang Jaya Kecamatan Kemiling Bandarlampung. Dilihat dari letaknya lokasi ini termasuk ke dalam Kota Madya dimana lahan hutan seringkali dialihgunakan menjadi lahan permukiman (perumahan), Namun pada lokasi ini masih terdapat kawasan hutan yang dikelola sendiri oleh masyarakatnya dengan menerapkan sistem penanaman agroforestri. Objek di dalam penelitian ini yaitu petani yang mengelola lahan milik (hutan rakyat) dengan sistem agroforestri.

Petani yang mengelola lahan milik (hutan rakyat) dengan sistem agroforestri berjumlah 30 petani. Menurut Arikunto (2012), jika jumlah populasi kurang dari 100 orang maka sampel yang diambil secara keseluruhan, berbeda dengan yang jumlah populasinya lebih dari 100 hanya dapat diambil $10-15 \%$ atau 20$25 \%$ dari jumlah populasi. Oleh karena 
itu, penelitian ini menggunakan metode sensus.

Data yang dikumpulkan pada penelitian ini meliputi data primer dengan melakukan wawancara kepada petani menggunakan bantuan kuisioner dengan pertanyaan sesuai dengan kebutuhan penelitian. Kemudian data sekunder yang diambil dengan cara mengutif data Badan Pusat Statistik Provinsi Lampung dalam angka meliputi kondisi umum (geografis) lokasi penelitian, jumlah masyarakat serta data-data yang berhubungan dengan penelitian. Data yang diperoleh kemudian dapat dianalisis secara deskriptif kualitatif untuk mengidentifikasi komposisi tanaman, dan melakukan analisis kuantitatif untuk menghitung pendapatan pertahun yang diperoleh petani.

\section{A. Identifikasi Komposisi Tanaman}

Identifikasi komposisi tanaman agroforestri dilakukan dengan membuat tabulasi dari hasil wawancara terhadap petani. Hasil tabulasi data tersebut dianalisis secara deskriptif-kualitatif terhadap jenis-jenis tanaman yang dibudidayakan oleh petani pada komposisi tanaman agroforestri.

Komposisi dibedakan berdasarkan tanaman utama yang merupakan tanaman dengan jumlah yang dominan pada suatu komposisi tanaman dan tanaman pengisi yaitu tanaman yang tidak mendominasi pada lahan hutan. Penggunaan kedua istilah tanaman tersebut bertujuan untuk memudahkan pengelompokkan komposisi tanaman yang dimiliki oleh petani yang dapat dilihat dari jumlah tanaman.

\section{B. Perhitungan Pendapatan Petani}

Pendapatan petani merupakan pendapatan yang diperoleh dari hasil panen yang diterima petani di setiap jenis tanaman yang dibudidayakan pada lahan yang dikelola dan biaya produksi (pengelolaan) yang dikeluarkan untuk mengelola lahan tersebut seperti pupuk dll. Pendapatan petani dapat diketahui dengan menghitung secara manual terhadap biaya penerimaan yang dikurang dengan biaya produksi menggunakan rumus sebagai berikut :

$$
\mathrm{Pd}=\mathrm{TR}-\mathrm{TC}
$$

Dimana :

$\mathrm{Pd}=$ Total pendapatan

$\mathrm{TR}=$ Total penerimaan

$\mathrm{TC}=$ Total biaya

\section{HASIL DAN PEMBAHASAN}

\section{Komposisi Tanaman Agroforestri}

Berdasarkan hasil penelitian yang telah dilakukan di Kelurahan Pinang Jaya bahwa jenis-jenis tanaman yang dibudidayakan oleh petani agroforestri diperoleh delapan komposisi tanaman utama dan tanaman pengisi lainnya, dimana tanaman utama dengan persentase sebesar 50\%-70\% sehingga keberadaan jenis tanamannya lebih mendominasi.. Data secara lengkap dapat dilihat pada Tabel 1 . 
JURNAL TENGKAWANG (2020)

Vol. 10 (2): 123 - 132

Tabel 1. Komposisi tanaman agroforestri di Kelurahan Pinang Jaya (Composition of agroforestry crops in Pinang Jaya District)

\begin{tabular}{|c|c|c|c|c|}
\hline Komposisi & $\begin{array}{l}\text { Tanaman } \\
\text { Utama }\end{array}$ & Tanaman Pengisi & $\begin{array}{l}\text { Jumlah } \\
\text { (KK) }\end{array}$ & $\begin{array}{l}\text { Persentase } \\
(\%)\end{array}$ \\
\hline $\mathrm{I}$ & Kakao \& Pisang & $\begin{array}{l}\text { Petai, Cempaka, Singkong, } \\
\text { Cabai, Kacang Tanah, } \\
\text { Medang, Durian, Alpukat, } \\
\text { Cengkeh, Waru, Jengkol, } \\
\text { Mangga, Kelapa, Jati, Bayur, } \\
\text { Tangkil, Pala }\end{array}$ & 14 & 46,7 \\
\hline II & Kakao \& Kopi & $\begin{array}{l}\text { Petai, Pisang, Waru, Lada, } \\
\text { Kelapa, Durian, Alpukat, } \\
\text { Singkong, Talas, Cabai }\end{array}$ & 4 & 13,3 \\
\hline III & $\begin{array}{l}\text { Kakao \& } \\
\text { Medang }\end{array}$ & $\begin{array}{l}\text { Petai, Pisang, Durian, } \\
\text { Cempaka, Singkong, Cabai, } \\
\text { Kemiri, Jabon }\end{array}$ & 2 & 6,7 \\
\hline IV & Kakao \& Petai & $\begin{array}{l}\text { Waru, Jati, Nangka, Durian, } \\
\text { Kelapa, Pisang, Bayur }\end{array}$ & 5 & 16,7 \\
\hline V & $\begin{array}{l}\text { Kakao \& } \\
\text { Cengkeh }\end{array}$ & $\begin{array}{l}\text { Petai, Pisang, Jengkol, } \\
\text { Pepaya, Pinang, Durian }\end{array}$ & 2 & 6,7 \\
\hline VI & Kakao \& Pala & $\begin{array}{l}\text { Petai, Pisang, Durian, Kemiri, } \\
\text { Kelapa, Jabon, Cempaka }\end{array}$ & 1 & 3,3 \\
\hline VII & Kopi \& Durian & Petai, Pala, Pisang, Pepaya & 1 & 3,3 \\
\hline VIII & Kopi \& Pisang & $\begin{array}{l}\text { Petai, Lada, Cengkeh, } \\
\text { Kelapa, Pepaya }\end{array}$ & 1 & 3,3 \\
\hline
\end{tabular}

(Sumber : Data Primer, 2020)

Pada Tabel 1 dapat dilihat bahwa jenis tanaman yang paling banyak atau dominan dibudidayakan oleh petani agroforestri yaitu tanaman kakao (Theobroma cacao) dan pisang (Musa $s p)$. Sama halnya dengan penelitian yang dilakukan oleh Nandini (2018) bahwa pisang dan kakao merupakan jenis tanaman yang lebih banyak ditanam dikawasan hutan sebagai tanaman campuran dengan komposisi agroforestri.

Berdasarkan hasil wawancara yang dilakukan terhadap responden diketahui bahwa petani lebih memilih untuk membudidayakan tanaman kakao dan pisang karena faktor jangka waktupemanenan yang dapat dilakukan dalam waktu singkat (setelah 6 bulan) dapat dipanen setiap dua minggu sekali serta pengelolaan yang cukup mudah hanya dengan melakukan penyiraman, penyiangan dan pemberian pupuk terhadap tanaman tersebut. Selain itu petani memilih tanaman perkebunan, Multi Purpose Trees Species (MPTS), dan pertanian yang dapat memberikan nilai ekonomis untuk dikombinasikan dengan tanaman utama. Tabel 1 menunjukkan bahwa petani memilih jenis tanaman perkebunan seperti kopi 
JURNAL TENGKAWANG (2020)

Vol. 10 (2): 123 - 132

dan tanaman pertanian meliputi cabai, kacang tanah, talas, pepaya, dan lada.

Sementara itu tanaman MPTS seperti durian, alpukat, jengkol, mangga, cengkeh, petai, nangka yang dapat di konsumsi serta dijual agar diperoleh pendapatan bagi petani agroforestri di Kelurahan Pinang Jaya. Hal ini sejalan dengan hasil penelitian Wulandari et al 2014) bahwa pada umumnya petani akan memilih untuk menanam jenis-jenis tanaman yang bernilai ekonomis dengan waktu panen yang tidak terlalu lama.

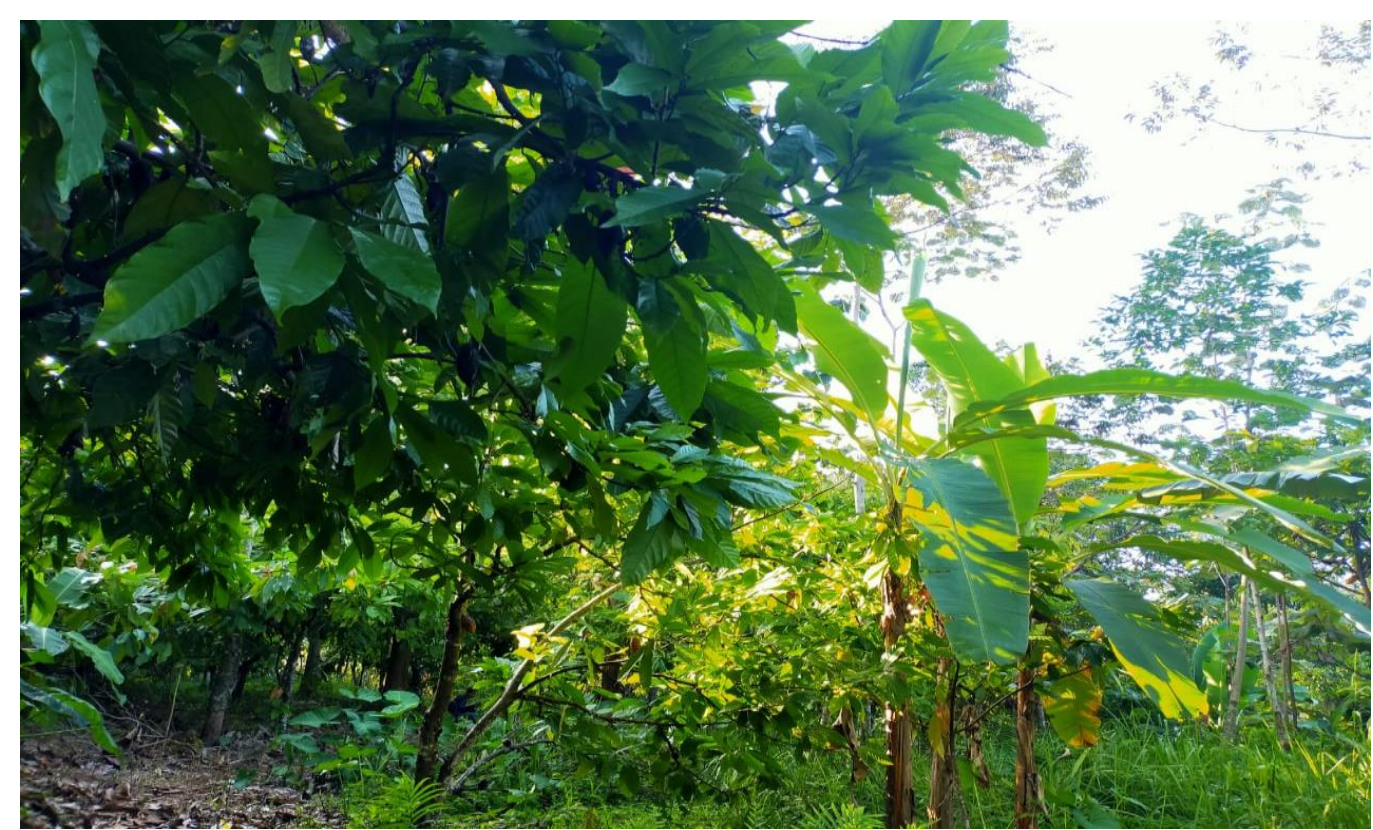

Gambar 1. Komposisi tanamanI yang dikelola oleh petani agroforestri pada hutan rakyat di Kelurahan Pinang Jaya

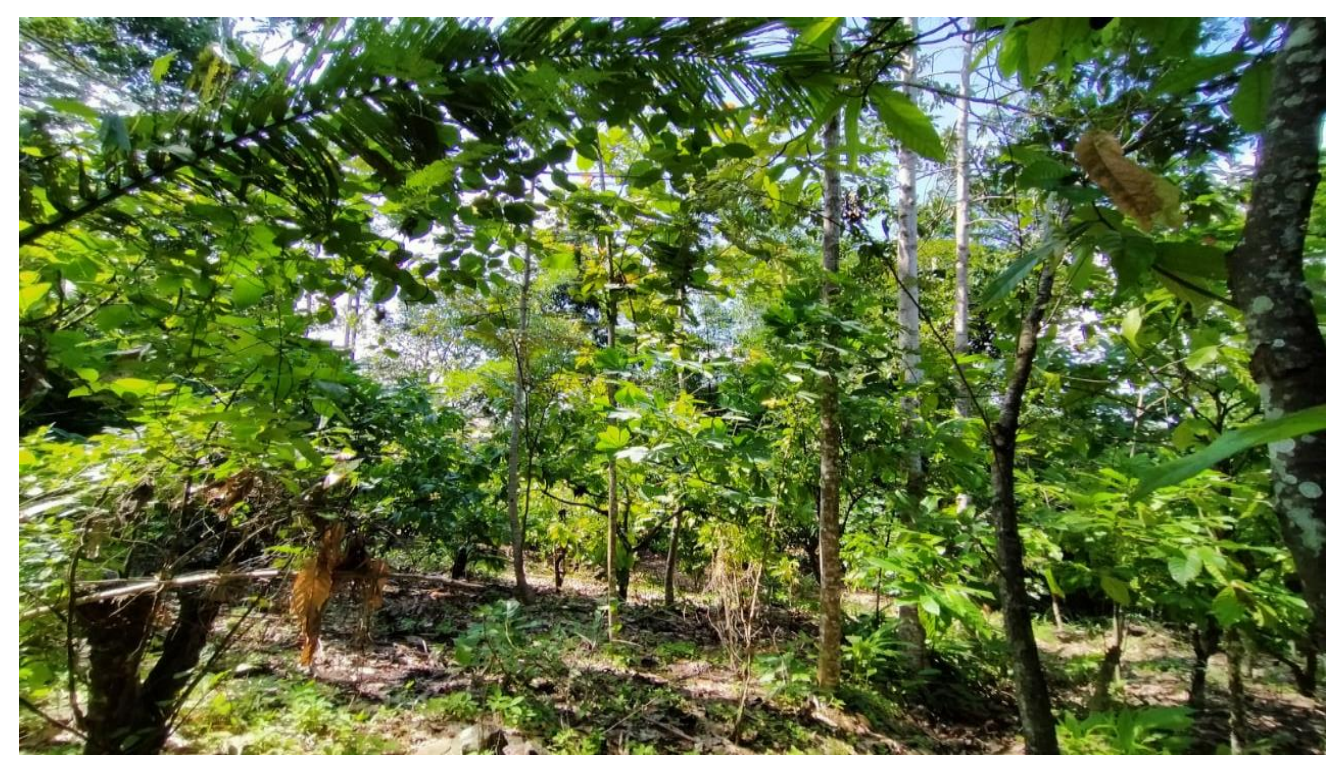

Gambar 2. Komposisi tanamanII yang dikelola oleh petani agroforestri pada hutan rakyat di Kelurahan Pinang Jaya 


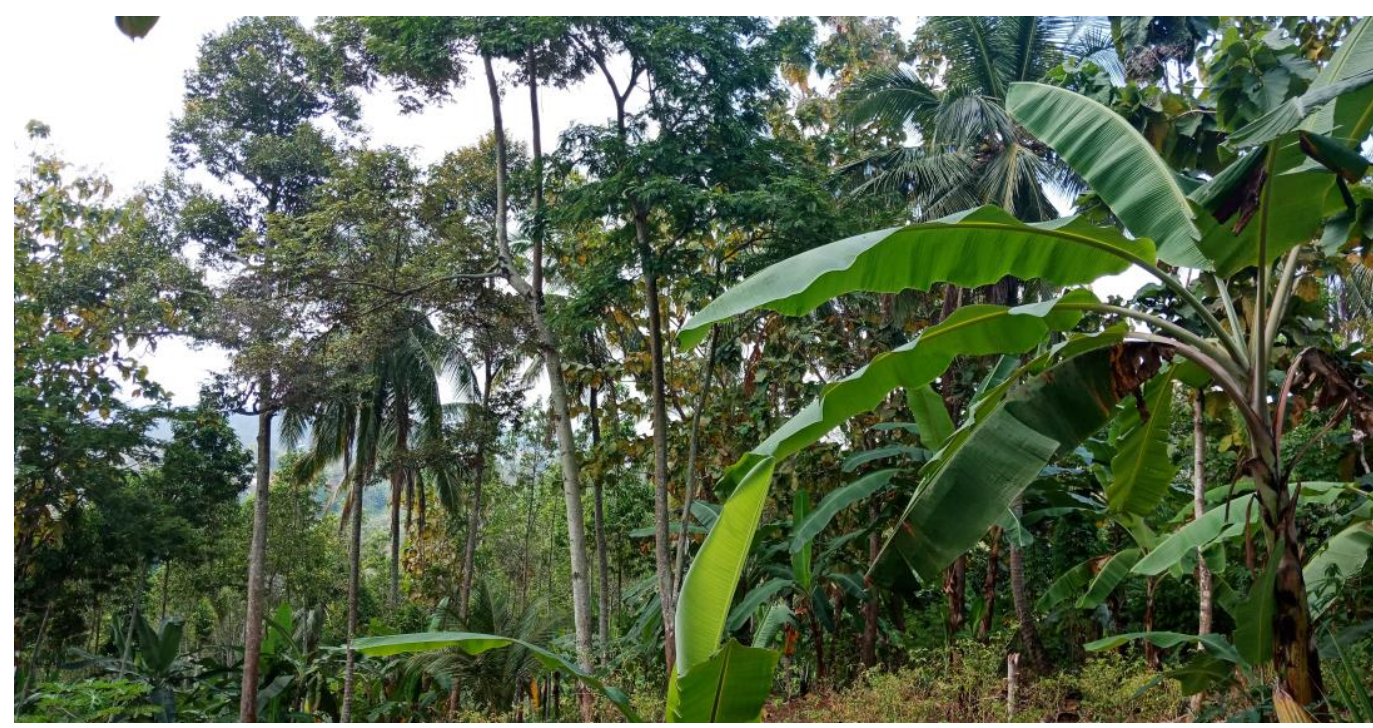

Gambar 3. Komposisi tanaman III yang dikelola oleh petani agroforestri pada hutan rakyat di Kelurahan Pinang Jaya

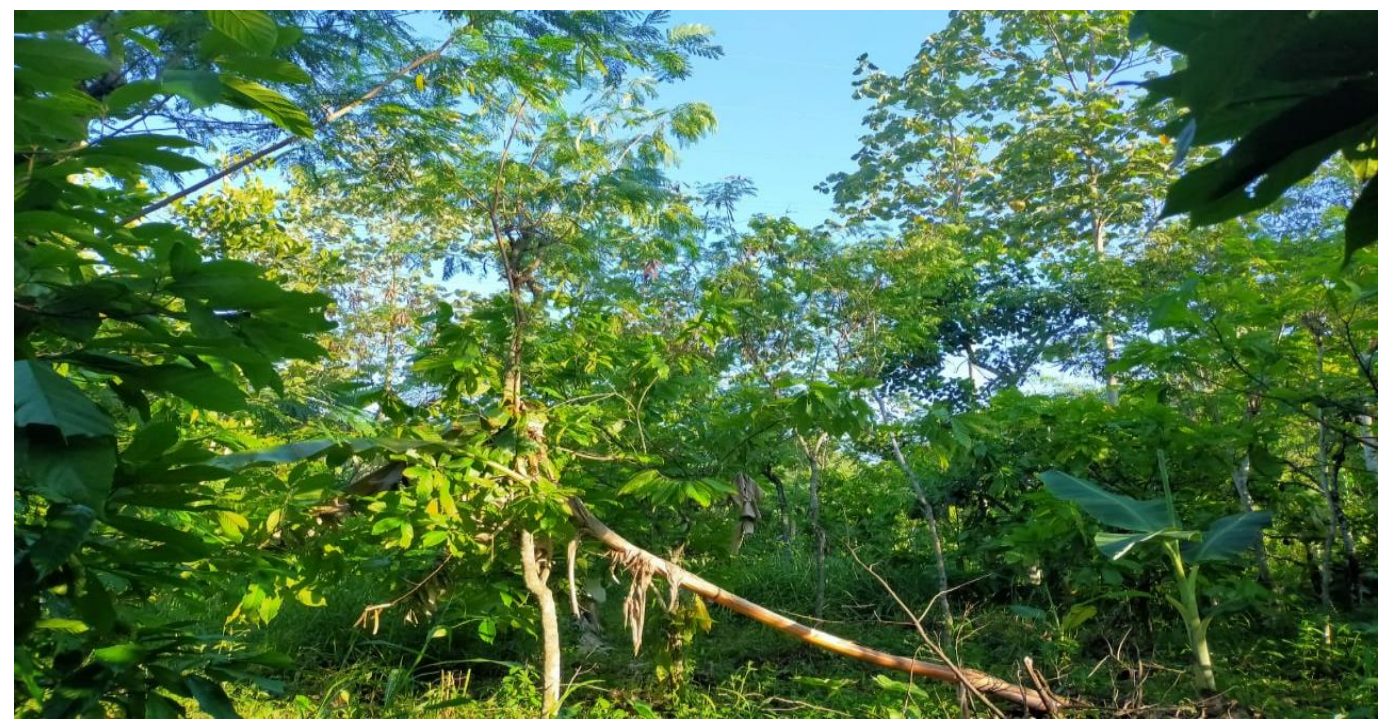

Gambar 3. Komposisi tanamanIV yang dikelola oleh petani agroforestri pada hutan rakyat di Kelurahan Pinang Jaya

\section{Pendapatan Petani Agroforestri}

Sistem agroforestri memberikan pendapatan bervariasi bagi petani yang terdiri pendapatan mingguan, bulanan bahkan tahunan. Tiap-tiap komposisi tanaman memberikan pendapatan yang berbeda-beda. Hal tersebut dipengaruhi oleh jenis-jenis tanaman yang dipilih oleh petani untuk dibudidayakan. Tanaman utama berupa kakao mampu memberikan pendapatan mingguan bagi petani dengan harga Rp 15.000/kg biji kakao yang sudah kering, sama hal nya dengan tanaman pisang yang mampu diperoleh dalam jangka pendek yaitu setiap bulan. Sedangkan Pendapatan yang diperoleh dalam jangka tahunan yaitu hasil panen tanaman MPTs diantaranya petai dan durian dengan pendapatan sebesar Rp. 1.000.000/tahun Secara lengkap pendapatan petani disajikan pada Tabel 2 . 
Tabel 2. Pendapatan petani agroforestri berdasarkan komposisi jenis tanaman The income of agroforestry farmers is based on the composition of the types of plants)

\begin{tabular}{|c|c|c|c|c|c|c|}
\hline Komposisi & $\begin{array}{c}\text { Luas } \\
\text { Lahan } \\
\text { Total } \\
\end{array}$ & $\begin{array}{c}\text { Jumlah } \\
\text { (KK) }\end{array}$ & $\begin{array}{c}\text { Penerimaan } \\
(\mathrm{Rp} / \mathrm{th})\end{array}$ & $\begin{array}{c}\text { Biaya } \\
\text { Produksi } \\
(\mathrm{Rp} / \mathrm{th})\end{array}$ & $\begin{array}{c}\text { Total } \\
\text { Pendapatan } \\
(\mathrm{Rp} / \mathrm{th})\end{array}$ & $\begin{array}{c}\text { Total } \\
\text { Pendapatan } \\
\text { (Rp/KK/Ha/th) }\end{array}$ \\
\hline I & 8,50 & 14 & 287.540 .000 & 3.630 .000 & 283.910 .000 & 2.385 .798 \\
\hline II & 2,00 & 4 & 55.200 .000 & 1.900 .000 & 53.300 .000 & 6.662 .500 \\
\hline III & 0,75 & 2 & 24.000 .000 & 450.000 & 23.550 .000 & 15.700 .000 \\
\hline IV & 1,75 & 5 & 71.400 .000 & 415.000 & 70.985 .000 & 8.112 .571 \\
\hline V & 0,50 & 2 & 26.500 .000 & 950.000 & 25.550 .000 & 25.550 .000 \\
\hline VI & 0,75 & 1 & 10.150 .000 & 400.000 & 9.750 .000 & 13.000 .000 \\
\hline VII & 1,50 & 1 & 18.000 .000 & 900.000 & 17.100 .000 & 11.400 .000 \\
\hline VIII & 1,50 & 1 & 22.000 .000 & 750.000 & 21.250 .000 & 14.166 .667 \\
\hline
\end{tabular}

(Sumber : Data Primer, 2020)

Tabel 2 diatas menunjukkan bahwa petani yang memiliki pendapatan tertinggi terdapat pada komposisi V dengan pendapatan sebesar $\mathrm{Rp}$ 25.550.00/kk/ha/tahun. Pada komposisi $\mathrm{V}$ tersebut didominasi oleh tanaman kakao (Theobroma cacao) dan cengkeh (Eugenia aromatica) yang dikombinasikan dengan tanaman petai (Parkia speciosa), pepaya (Carica papaya),pisang (Musa sp), jengkol (Pithecellobium lobatum),pinang (Pinanga kuhlii),dan durian (Durio zibethinus).

Komposisi yang memiliki pendapatan paling rendah terdapat pada komposisi I dengan rata-rata pendapatan sebesar Rp 2.385.798/kk/ha/tahun. Pada komposisi ini didominasi oleh kakao (Theobroma cacao) dan pisang (Musa spp) yang dikombinasikan dengan tanaman petai (Parkia speciosa), durian (Durio zibethinus), alpukat (Persea americana), cengkeh (Eugenia aromatica), jengkol (Pithecellobium lobatum), singkong (Manihot esculenta), cabai (Capsicum sp), dan kacang tanah (Arachis hypogaea), medang (Litseaangulata), cempaka (Magnolia champaca), dan waru (Hibiscus tiliaceus). Hal ini terjadi karena komposisi I membudidayakan tanamannya secara acak/ dicampur dengan tanaman lainnya serta tanaman lebih banyak dikonsumsi pribadi daripada dijual, sehingga pemeliharaan terhadap tanaman tersebut kurang maksimal, mengakibatkan pendapatan yang diperoleh petani hanya dari tanaman utama berupa kakao yang dijual biji nya dalam keadaan basah maupun kering dan tanaman pengisi lainnyadengan jumlah sangat sedikit. Sejalan dengan penelitian Wanderi et al (2019) bahwa semakin sedikit jenis tanaman yang bernilai komersil menyebabkan rendahnya pendapatan yang diperoleh petani.

Pengelolaan tanaman agroforestri pada komposisi VII belum menggunakan bibit-bibit dengan kualitas yang baik dikarenakan petani lebih memilih untuk memanfaatkan bibit yang tersedia dari hasil persemaian mereka sendiri. Kegiatan pembudidayaan tanaman tersebut tidak 
disertai dengan pemberian pestisida, karena petani hanya menggunakan pupuk kandang. Pengelolaan lahan dengan sistem agroforestri merupakan salah satu cara untuk memanfaatkan lahan agar dapat memberikan nilai ekonomi terhadap petani namun tetap menjaga kelestarian lingkungannya.

Sementara itu penggunaan sistem agroforestri tidak hanya sekedar melakukan pengkombinasian antara tanaman kehutanan dengan tanaman pertanian, perkebunan, dan lain-lain. Melainkan perlu untuk memperhatikan dalam pemilihan jenis tanaman, tata letak tanaman (pola), perawatan yang maksimal (pupuk, penyiraman, penyiangan). Hal tersebut diperlukan agar petani dapat memperoleh nilai ekonomis yang lebih besar dari lahan yang mereka kelola.

\section{KESIMPULAN}

Komposisi tanaman agroforestri yang terdapat di Kelurahan Pinang Jaya sebanyak 8 komposisi dengan jenis tanaman yang lebih dominan (utama) adalah kakao yang dikombinasikan dengan tanaman jenis lainnya sebagai tanaman pengisi.

Pendapatan yang paling tinggi terdapat pada komposisi $\mathrm{V}$ dengan jenis tanaman utama berupa kakao dan cengkeh, memperoleh pendapatan sebesar Rp 25.550.00/KK/ha/tahun. Sementara pendapatan paling rendah pada komposisi I dengan pendapatan sebesar Rp 2.385.798/KK/ha/tahun dengan jenis tanaman utama berupa kakao dan pisang.

\section{SARAN}

Petani agroforestri pada hutan rakyat di Kelurahan Pinang Jaya harus lebih maksimal dalam melakukan pengelolaan lahan yang dimiliki dengan sistem agroforestri salah satunya menerapkan pengelolaan lahan dengan pola tanam berseling (Alley Cropping / Alternative Rows) agar dapat memperoleh pendapatan yang mampu memenuhi kebutuhan hidup sehari-hari maupun kebutuhan dalam jangka panjang dan lahan tertata dengan bagus serta dapat melindungi lahan agar tidak mudah longsor.

\section{UCAPAN TERIMA KASIH}

Terimakasih diucapkan kepada yang sudah membantu penelitian dan memberikan masukan-masukan pada penulisan ini dan Bapak Agus yang sudah membantu dalam wawancara ke setiap rumah petani di Kelurahan Pinang Jaya.

\section{DAFTAR PUSTAKA}

Anwar, S. 2012. Pola Tanam Tumpangsari. Agroekoteknologi. Litbang : Deptan.

Arikunto, S. 2012. Prosedur Penelitian Suatu Pendekatan Praktek. Buku. Rineka Cipta. Jakarta.

Ayu, H.Y., Qurniati, R., dan Hilmanto, R. 2015. Analisis finansial dan komposisi tanaman dalam rangka persiapan pengajuan izin $\mathrm{hkm}$ (studi kasus desa margosari kecamatan pagelaran utara kabupaten pringsewu). $J$. SylvaLestari. 3(1): 31-40.

Badan Pusat Statistik. 2019. Provinsi Lampung dalam Angka Tahun 2019. Bandar Lampung : Badan Pusat Statistik 
Mamuko, F., Walangitan, H., dan Tilaar, W. 2016. Persepsi dan partisipasi masyarakat dalam upaya rehabilitasi hutan dan lahan di kabupaten bolaang mongondow timur. J. Eugenia. 22(2): 80-92.

Mbolo, M.M.A., Zekeng, J.C., Mala, W.A., Fobane, J.L., Chimi, C.D., Ngavounsia, T., Nyako, C.M., Menyene, L.F.E., dan Tamanjong, Y.V.2016. The role of cocoa agroforestry systems in conserving forest treediversity in the central region of cameroon. Journal of Agroforestry Systems. 90(4): 577-590.

Nandini, R. 2018. Analisis keuntungan usahatani agroforestri kemiri, coklat, kopi dan pisang di hutan kemasyarakatan sesaot, lombok barat. J. Faloak 2(1): 1-12.

Olivi, R., Qurniati, R., dan Firdasari.2015. Kontribusi agroforestri terhadap pendapatan petani didesa sukoharjo 1 kecamatan sukoharjo kabupaten pringsewu. J. Sylva Lestari. 3(2):1-12.

Qurniati R., Febryano IG., dan Zulfiani D. 2017. How Trust Influence Social Capital to Support Collective Action in Agroforestry Development? Jurnal Biodiversitas 18(3): 1201-1206.

Syofiandi, R. R., Hilmanto, R. dan Herwanti, S. 2016. Analisis pendapatan dan kesejahteraan petani agroforestri di kelurahan sumber agung kecamatan kemiling kota bandar lampung. Jurnal Sylva Lestari. 4(2): 7-26.

Tiurmasari, S., Hilmanto, R. dan Herwanti, S. 2016. Analisis vegetasi dan tingkat kesejahteraan masyarakat pengelola agroforestri di desa sumber agung kecamatan kemiling kota bandar lampung. Jurnal Sylva Lestari. 4(3) : 7182.

Wanderi, Qurniati, R. dan Kaskoyo, H. 2019. Kontribusi tanaman agroforestri terhadap pendapatan dan kesejahteraan petani. J. Sylva Lestari. 7(1) : 118-127

Widiarti, A., dan Prajadinata, S. 2008. Karakteristik Hutan Rakyat Pola Kebun Campuran. Buku. Institut Pertanian Bogor. Bogor. 145 hlm.

Wulandari, C., Budiono, P., Yuwono, S. B. dan Herwanti, S. 2014. Adoption of agro-forestry patterns and crop systems around register 19 forest park, lampung province, indonesia. J. MHT. 20(2): 86-93. 